\title{
Resumos de Artigos
}

Toxicidade pulmonar em pacientes recebendo baixas doses de amiodarona.

Ott MC, Khoor A, Leventhal JP, Paterick TE, Burger $\mathrm{CD}$. Pulmonary toxicity in patients receiving low-dose amiodarone. Chest 2003;123: 646-51.

Objetivo: Demonstrar que a amiodarona, mesmo quando utilizada em baixas doses, acarreta efeitos adversos para o pulmão, através do estudo de casos de oito pacientes.

Material e método: Foram avaliados oito pacientes, sete deles masculinos, recebendo 200 mg de amiodarona diários, com média de idade de 77 anos. Os pacientes vinham recebendo a medicação por um período médio de dois anos. Para se chegar ao diagnóstico, foram realizadas radiografias, biópsias, broncoscopias, exames laboratoriais, ecocardiografia, além do registro de todos os achados clínicos.

Resultados: Os sintomas apresentados pelos pacientes foram dispnéia (sete pacientes) e tosse (três pacientes). Um dos pacientes teve início dos sintomas após cirurgia cardíaca. Todos os pacientes foram submetidos à radiografia de tórax e seis fizeram tomografia computadorizada do tórax. Os achados foram variados, mas sempre bilaterais. Nenhum paciente tinha evidência clínica de insuficiência cardíaca. 0 tratamento envolveu a interrupção do uso de amiodarona e três pacientes receberam corticóides. Cinco pacientes apresentaram melhora dos sintomas e quatro melhoraram radiologicamente apenas com a interrupção do uso da amiodarona. Os três pacientes que receberam corticóides obtiveram melhora; no entanto, um deles voltou a apresentar sintomas com a descontinuidade do uso destes. Um paciente morreu de insuficiência respiratória progressiva e em outro não pôde ser feito o seguimento. 0 diagnóstico de toxicidade pulmonar induzida pela amiodarona foi feito clinicamente em seis pacientes. Um dos pacientes, um homem branco de 67 anos, ilustra bem a típica evolução que resultou no diagnóstico clínico positivo. Ele era portador de doença miocárdica isquêmica, que evoluiu com fibrilação e "flutter" atrial com alta resposta ventricular, sendo iniciado o uso de amiodarona em dose de $200 \mathrm{mg}$, que foi aumentada após três dias para 400 mg ao dia. Aproximadamente três meses depois, o paciente iniciou quadro de dispnéia, sem outros comemorativos. Radiografia de tórax revelou infiltrações alvéolo-intersticiais bilaterais, sem alterações no tamanho cardíaco, vasculatura pulmonar normal e sem derrame pleural. Apenas com a descontinuidade do uso da amiodarona, dois meses mais tarde, a dispnéia já tinha sido resolvida e após quatro meses, a infiltração pulmonar já havia desaparecido. 0 seguimento durou três anos, sem alterações clínico-radiológicas subseqüentes.

Conclusão: Fibrilação atrial é uma arritmia extremamente comum em pacientes idosos e naqueles com doença cardíaca. Pesquisas recentes mostraram que a amiodarona em baixas doses é efetiva e associada a poucos efeitos colaterais. Toxicidade pulmonar induzida pela amiodarona tem sido observada em até 10\% dos pacientes que fazem uso desta droga, que pode variar desde afecção subaguda a até rapidamente progressiva e fatal. Seus efeitos tóxicos parecem ter relação com a dose utilizada e a duração do tratamento, sendo maior o risco com doses maiores ou iguais a $400 \mathrm{mg}$ por dia. 0 objetivo deste artigo é ressaltar o fato de que baixas doses de amiodarona estão associadas com algum risco de toxicidade pulmonar.

\section{Leticia Pereira Gonçalves \\ Médica pós-graduanda do Departamento de Radiologia da UFF}

\section{Toxicidade pulmonar por amiodarona no} pós-operatório tardio.

Fernández AA, Sala AR, Mediano 0, Torres I, Moreno I. Toxicidad pulmonar por amiodarona en el post-operatorio tardio. Med Interna (Madrid) 2003;20:419-20.

Objetivo: Apresentação de um caso de toxicidade pulmonar pela amiodarona em um paciente masculino de 55 anos, tabagista, em que foram analisados, principalmente, os aspectos clínicos, patológicos e radiológicos.

Resultados: 0 paciente em questão é um cardiopata que fora submetido à cirurgia de substituição de válvula cardíaca por doença reumática prévia e, desde então, faz uso de amiodarona, entre outras medicações. 0 tratamento, inicialmente, foi feito com $400 \mathrm{mg}$ diários de amiodarona e, a posteriori, $200 \mathrm{mg}$ ao dia. Ao exame físico, o paciente apresentava-se em mau estado geral, taquicárdico e com crepitações pulmonares bilaterais. As radiografias do tórax evidenciaram infiltrações alvéolo-intersticiais bilaterais. Estes achados se confirmaram na tomografia computadorizada. 0 paciente foi submetido à broncoscopia diagnóstica. No lavado broncoalveolar não houve crescimento de germes nas culturas e a baciloscopia foi negativa, sendo encontrada grande quantidade de macrófagos. 0 paciente teve o diagnóstico de pneumonite tóxica secundária ao uso de amiodarona e iniciou o tratamento com oxigenioterapia, diuréticos, digoxina e metilprednisona, além de ter cessado o uso da amiodarona. Apresentou melhora clínica e teve alta após 44 dias de internação.

Conclusão: A amiodarona é um fármaco anti-arrítmico muito eficaz no tratamento de arritmias ventriculares e supraventriculares. Há anos são conhecidos os efeitos desta droga, como danos hepáticos, tireoidianos e pulmonares. Os efeitos do seu uso crônico são os mais conhecidos, embora ultimamente também têm sido relatados casos de toxicidade aguda. Atualmente, não se dispõe de nenhuma prova diagnóstica específica para diagnosticá-la, mas há de se estar atento a pacientes com sintomas respiratórios em uso de amiodarona. 0 diagnóstico baseia-se na história clínica e na detecção de macrófagos no lavado broncoalveolar, após terem sido descartadas outras possíveis causas de doenças pulmonares.

Leticia Pereira Gonçalves Médica pós-graduanda do Departamento de Radiologia da UFF 